This Provisional PDF corresponds to the article as it appeared upon acceptance. Fully formatted PDF and full text (HTML) versions will be made available soon.

\title{
Takotsubo Cardiomyopathy Secondary To Intracranial Hemorrhage
}

International Journal of Emergency Medicine 2014, 7:33 doi:10.1186/s12245-014-0033-4

Mai Shimada (mshimada@maimonidesmed.org)

Jonathan Rose (jrose@bhmcny.org)

Published online: 04 September 2014

\author{
ISSN $\quad 1865-1380$ \\ Article type Case report \\ Submission date 12 April 2014 \\ Acceptance date 13 August 2014 \\ Article URL http://www.intjem.com/content/7/1/33
}

This peer-reviewed article can be downloaded, printed and distributed freely for any purposes (see copyright notice below).

For information about publishing your research in International Journal of Emergency Medicine go to http://www.intjem.com/authors/instructions/

For information about other SpringerOpen publications go to http://www.springeropen.com 


\title{
Takotsubo cardiomyopathy secondary to intracranial hemorrhage
}

\author{
Mai Shimada ${ }^{{ }^{*}}$ \\ * Corresponding author \\ Email: mshimada@maimonidesmed.org \\ Jonathan D Rose ${ }^{2}$ \\ Email: jrose@bhmcny.org \\ ${ }^{1}$ Maimonides Medical Center, New York, NY 11219, USA \\ ${ }^{2}$ Brookdale University Hospital and Medical Center, New York, NY 11212, USA
}

\begin{abstract}
Patients suffering from aneurysmal subarachnoid hemorrhage often present with electrocardiogram (ECG) abnormalities that mimic cardiac ischemia, but documented left ventricular regional wall-motion dysfunction has rarely been reported. This report is intended to raise the awareness of possible ECG changes secondary to subarachnoid hemorrhage (SAH). We cared for a 55-year-old female with an acute aneurysmal subarachnoid hemorrhage, whose evaluation was delayed and complicated by the presence of Takotsubo cardiomyopathy (TCM). Aneurysmal subarachnoid hemorrhage may induce Takotsubo cardiomyopathy that can present as an acute ST-elevation myocardial infarction. Physicians need to be aware of this possibility since it can lead to significant delays and treatment options for the patient.
\end{abstract}

\section{Keywords}

Takotsubo; Cardiomyopathy; Apical ballooning syndrome; Subarachnoid hemorrhage; Intracranial hemorrhage; ECG abnormalities

\section{Background}

Aneurysmal subarachnoid hemorrhage (SAH) has a reported mortality of 30 to $50 \%$. Death results from the direct neurologic complications from the bleeding and cerebral ischemia. Although the mechanism has not been fully elucidated and may be due to neurohormonal activation and catecholamine surges, cardiac manifestations are commonly reported in the setting of SAH [1]. These may include electrocardiogram (ECG) changes of QT prolongation and $\mathrm{T}$ wave inversion, elevated biochemical markers of myocardial damage and heart failure, and decreased left ventricular function [1-3].

Takotsubo cardiomyopathy (TCM) is characterized by transient hypokinesis of the left ventricle that is often brought on by stress. It has been estimated that the incidence of TCM in SAH patients may be as high as 4 to 15\% [4]. Since the treatment of TCM differs from that of acute myocardial infarction, it is important to be able to make the diagnosis early in the course of these patients. We report a case of a patient with aneurysmal subarachnoid 
hemorrhage whose evaluation and diagnosis were complicated by the presence of TCM. This case report illustrates the importance of recognizing TCM as a possible consequence of SAH.

\section{Case presentation}

A 55-year-old female was at home sitting at a table when her family noted that she suddenly lost consciousness. Paramedics were called and found her unresponsive with agonal respirations. Her blood glucose was measured at $109 \mathrm{mg} / \mathrm{dL}$, intubation was attempted but was not successful, and rescue breathing by bag-valve-mask was performed as she was transported to the hospital.

On arrival in the emergency department, the patient was unresponsive and making sonorous breath sounds. Her heart rate was 138 beats per minute, respirations 22 breaths per minute, blood pressure $154 / 103 \mathrm{mmHg}$, and oxygen saturation $96 \%$ on $100 \% \mathrm{O}_{2}$. Unable to maintain her airway as a consequence of her mental status and believed to be in need of emergent CT imaging of her brain upon arrival, she was intubated. No evidence of head or body trauma was noted, and pupils were $4 \mathrm{~mm}$ bilaterally and equal but not reactive. Her Glasgow Coma Score was 9 (E4, V1, M4). The rest of her physical exam was unremarkable except for a healing incision over the left great toe.

Past medical history obtained from her family was significant for hypertension, and her current medications included enalapril, amlodipine, and metoprolol. They also noted that she had undergone a left foot surgery 3 weeks prior to her presentation. They denied any history of tobacco, alcohol, or illicit drug use.

The patient was rapidly intubated and a stroke code called. At the same time, an ECG was obtained and revealed evidence of an inferolateral ST-segment elevation myocardial infarction (STEMI) (Figure 1). Although resulting after disposition, her initial laboratories revealed a $\mathrm{pH}$ of 7.26 and a lactate of $7.1 \mathrm{mmol} / \mathrm{L}$. Serum chemistries demonstrated a sodium of $137 \mathrm{mmol} / \mathrm{L}$, potassium of $3.4 \mathrm{mEq} / \mathrm{L}$, chloride of $99 \mathrm{mEq} / \mathrm{L}$, bicarbonate of $25 \mathrm{mEq} / \mathrm{L}$, glucose of $234 \mathrm{mg} / \mathrm{dL}$, creatinine of $0.9 \mathrm{mg} / \mathrm{dL}$, and calcium of $9.2 \mathrm{mg} / \mathrm{dL}$. The patient's white blood cell count was $15.6 \times 103 / \mathrm{uL}$, hemoglobin $14.2 \mathrm{~g} / \mathrm{dL}$, platelet count $298 \times$ $103 / \mathrm{uL}$, prothrombin time $10.6 \mathrm{~s}$ (INR of 0.9 ), and partial thromboplastin time $24.3 \mathrm{~s}$. Her cardiac enzymes revealed a CKMB fraction of 3.4 units/L and a troponin I of $0.16 \mathrm{ng} / \mathrm{mL}$ (ref range 0.00 to 0.04 ).

\section{Figure 1 ECG obtained upon patient's arrival in the emergency department.}

Unstable and now with a suspected acute ST-elevation myocardial infarction, Cardiology was consulted and she was taken directly to the cardiac catheterization laboratory for revascularization prior to obtaining a head computer tomography (CT) scan. During the procedure, the patient received 2,500 units of heparin intraarterially but was not treated with any additional antiplatelet or anticoagulant therapy. The cardiac catheterization demonstrated normal coronary arteries with hypokinesis of the left ventricle.

Then, approximately $3 \mathrm{~h}$ after her arrival at the hospital, a noncontrast head CT was obtained that demonstrated a subarachnoid hemorrhage in the cisternal spaces around the cerebellum, in the prepontine and medullary cisterns and perimesencephalic and interpeduncular cisterns. This was associated with bilateral acute subdural hematomas, intraventricular hemorrhage, 
tonsillar and supratentorial herniation, and obstructive hydrocephalus (Figure 2). The patient was then transferred to the cardiac intensive care unit where Neurosurgery and Neurology were consulted and determined that she was clinically brain dead. With family involvement, assisted ventilation and vasopressor support was withdrawn and the patient expired on her fourth hospital day.

\section{Figure 2 Noncontrast head computed tomogram obtained once the patient arrived in} the intensive care unit.

\section{Discussion}

Aneurysmal subarachnoid hemorrhage carries a high mortality rate, and the main cause of morbidity and death is directly related to cerebral ischemia and intracranial mass effect [1]. ECG abnormalities have long been associated with the presentation of SAH, and elevations in troponin, CK-MB, and BNP are well-known harbingers of poor outcome [3,5,6]. It has been reported that $61.9 \%$ of patients with SAH will present with an abnormal ECG and that 20 to $30 \%$ of patients will manifest a secondary cardiomyopathy [7].

Several mechanisms for the cardiac complications that occur after SAH have been suggested. A generally accepted hypothesis is that the sympathetic stimulation induces catecholamine release in the myocardium leading to impaired systolic and diastolic function, repolarization abnormalities, and direct myocardial damage [3,7,8]. In addition, it has been reported that during the acute phase of $\mathrm{SAH}$, there is an increase in aortic wall stiffness leading to higher left ventricular pressures [8]. These mechanisms may be responsible for the etiology for the TCM that occurred in our patient.

TCM most commonly occurs in women $(89 \%)$ with a mean age of 68 . Forty-six percent of cases are triggered by intense emotional or physical stress. The diagnostic criteria for TCM include the following: transient hypokinesis, akinesis, or dyskinesis in the left ventricular mid-wall segments with or without apical involvement; absence of obstructive coronary disease; new ECG abnormalities or modest elevation in cardiac troponin; and absence of pheochromocytoma and myocarditis [9]. In general, TCM is a transient disorder that can be managed with supportive therapy such as angiotensin-converting-enzyme (ACE) inhibitors, beta-blockers, and diuretics [4,10]. Aspirin has also been suggested in the presence of coexisting coronary atherosclerosis $[10,11]$.

Our case represented a delay to diagnosis in a patient with TCM who appeared to be suffering from an acute ST-elevation myocardial infarction. Although the initial differential diagnosis included the potential for a cerebral vascular event, the presence of STEMI criteria on her ECG along with her unstable condition led us to investigate her apparent cardiac pathology in the catheterization lab prior to obtaining a head CT. Given the patient's poor prognosis when she arrived, it is unclear if the heparin she received during cardiac catheterization worsened her SAH or changed her outcome. As emergency physicians, we need to be aware of the danger of anchoring to a single diagnosis, which can easily blind us from other possible pathologies. 


\section{Conclusions}

Aneurysmal subarachnoid hemorrhage may induce Takotsubo cardiomyopathy that can present as an acute ST-elevation myocardial infarction. Physicians need to be aware of this possibility since it can lead to significant delays and treatment options for the patient.

\section{Competing interests}

The authors declare that they have no competing interests.

\section{Authors' contributions}

JR cared for the patient and participated in editing the manuscript. MS conceived of and drafted the manuscript and is responsible for its contents. Both authors read and approved the final manuscript.

\section{References}

1. Solenski NJ, Haley EC, Kassell NF, Kongable G, Germanson T, Truskowski L, Torner JC: Medical complications of aneurismal subarachnoid hemorrhage: a report of the multicenter, cooperative aneurysm study. Crit Care Med 1995, 23:1007-1017.

2. Jung JH, Min PK, Rim SJ, Ha JW, Chung N, Lee KC: Are electrocardiographic changes in patients with acute subarachnoid hemorrhage associated with Takotsubo cardiomyopathy. Cardiology 2010, 115:98-106.

3. Naidech AM, Kreiter KT, Janjua N, Ostapkovich ND, Parra A, Commichau C, Fitzsimmons BF, Connolly ES, Mayer SA: Cardiac troponin elevation, cardiovascular morbidity, and outcome after subarachnoid hemorrhage. Circulation 2005, 112:28512856.

4. Lee VH, Connolly HM, Fulgham JR, Manno EM, Brown RD Jr, Wijdicks EF: Takotsubo cardiomyopathy in aneurismal subarachnoid hemorrhage: an underappreciated ventricular dysfunction. J Neurosurg 2006, 105:264-270.

5. van der Bilt IA, Hasan D, Vandertop WP, Wilde AA, Algra A, Visser FC, Rinkel GJ: Impact of cardiac complications on outcome after aneurismal subarachnoid hemorrhage: a meta-analysis. Neurology 2009, 72:635-642.

6. Hravnak M, Frangiskakis JM, Crago EA, Chang Y, Tanabe M, Gorcsan J 3rd, Horowitz MB: Elevated cardiac troponin 1 and relationship to persistence of electrocardiographic and echocardiographic abnormalities after aneurismal subarachnoid hemorrhage. Stroke 2009, 40:3478-3484.

7. Banki N, Kopelnik A, Tung P, Lawton MT, Gress D, Drew B, Dae M, Foster E, Parmley $\mathrm{W}$, Zaroff $\mathrm{J}$ : Prospective analysis of prevalence, distribution, and rate of recovery of left ventricular systolic dysfunction in patients with subarachnoid hemorrhage. $J$ Neurosurg 2006, 105:15-20. 
8. Papanikolaou J, Makris D, Karakitsos D, Saranteas T, Karabinis A, Kostopanagiotou G, Zakynthinos E: Cardiac and central vascular functional alterations in the acute phase of aneurismal subarachnoid hemorrhage. Crit Care Med 2012, 40:223-232.

9. Nunez-Gil IJ, Molina M, Bernardo E, Borja I, Borja R-M, García-Rubira JC, Vivas D, Feltes G, Luaces M, Alonso J, Zamorano J, Macaya C, Fernández-Ortiz A: Tako-tsubo syndrome and heart failure: long-term follow-up. Rev Esp Cardiol 2012, 65:996-1002.

10. Bybee KA, Kara T, Prasad A, Lerman A, Barsness GW, Wright RS, Rihal CS: Systematic review: transient left ventricular apical ballooning: a syndrome that mimics ST-segment elevation myocardial infarction. Ann Intern Med 2004, 141:858-865.

11. Prasad A, Lerman A, Rihal CS: Apical ballooning syndrome (Tako-Tsubo or stress cardiomyopathy): a mimic of acute myocardial infarction. Am Heart J 2008, 155:408417. 
Hecad 5.0 Hazs

99: 20

im: 12 (POS)

$x: 51,3785$

Mog: 1x:

(Gsan)

R

$1300 \mathrm{ky}$ 됟․ 5.cthis TH: 00 1.08 T5: 960 SPR: 0.80

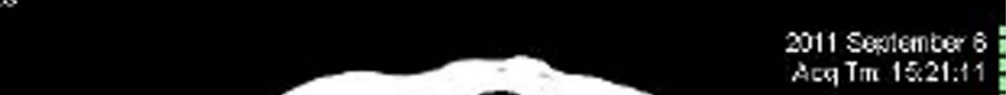

